\title{
High Cholesterol Feeding May Induce Tubular Dysfunction Resulting in Hypomagnesemia
}

\author{
Vanessa F. Favaro Fabíola M. Oshiro-Monreal Ana Carolina de Bragança \\ Lucia Andrade Antonio Carlos Seguro Claudia M.B. Helou \\ Laboratório de Pesquisa Básica (LIM-12), Hospital das Clínicas, Faculdade de Medicina da Universidade de \\ São Paulo, São Paulo, Brazil
}

\section{Key Words}

Hypomagnesemia • Hypercholesterolemia • Magnesium • TRPM6 $\cdot$ Renal hemodynamic $\cdot$ Renal transporter $\cdot$ Renal dysfunction

\begin{abstract}
Background/Aims: Hypomagnesemia may induce hypercholesterolemia, but the contrary has not been described yet. Thus, magnesium homeostasis was evaluated in rats fed a cholesterol-enriched diet for 8 days. This study has a relevant clinical application if hypomagnesemia, due to hypercholesterolemia, is confirmed in patients with long-term hypercholesterolemia. Methods: Both hypercholesterolemic (HC) and normocholesterolemic rats (NC) were divided into sets of experiments to measure hemodynamic parameters, physiological data, maximum capacity to dilute urine $\left(\mathrm{C}_{\mathrm{H}_{2} \mathrm{O}}\right)$, variations $(\Delta)$ in $\left[\mathrm{Ca}^{2+}\right]_{\mathrm{i}}$ and the expression of transporter proteins. Results: $\mathrm{HC}$ developed hypomagnesemia and showed high magnesuria in the absence of hemodynamic abnormalities. However, the urinary sodium excretion and $\mathrm{C}_{\mathrm{H}_{2} \mathrm{O}}$ in $\mathrm{HC}$ was similar to NC. On the other hand, the responses to angiotensin II by measuring $\Delta\left[\mathrm{Ca}^{2+}\right]_{\mathrm{i}}$ were higher in the thick ascending limb of Henle's loop (TAL) of HC than NC. Moreover, high expression of the cotransporter NKCC2 was found
\end{abstract}

in renal outer medulla fractions of $\mathrm{HC}$. Taken together, the hypothesis of impairment in TAL was excluded. Actually, the expression of the epithelial $\mathrm{Mg}^{2+}$ channel in renal cortical membrane fractions was reduced in HC. Conclusion: Impairment in distal convoluted tubule induced by hypercholesterolemia explains high magnesuria and hypomagnesemia observed in $\mathrm{HC}$.

Copyright $\odot 2011$ S. Karger AG, Basel

\section{Introduction}

Hypercholesterolemia is one of the major risk factors in the development of cardiovascular diseases including hypertension and ischemic damage in distinct organs. Currently, atherosclerosis is considered an inflammatory disease in which cytokines, proteases and vasoactive molecules are released from the endothelium due to oxidative stress generated by LDL cholesterol accumulated in the intima $[1,2]$. Consequently, an impairment of endothelium-dependent vasodilatation occurs and nonvascular tissues may also be targeted by the inflammatory effector mechanism [3]. Hence, hypercholesterolemia may induce vascular and nonvascular injuries in the organs.

\section{KARGER}

Fax +4161306 1234 E-Mail karger@karger.ch www.karger.com
(C) 2011 S. Karger AG, Basel

$1420-4096 / 12 / 0353-0137 \$ 38.00 / 0$

Accessible online at:

www.karger.com $/ \mathrm{kbr}$
Claudia M.B. Helou

Laboratório Pesquisa Básica (LIM-12)

Faculdade de Medicina da Universidade de São Paulo

Av. Dr. Arnaldo 455 sala 3310, São Paulo, SP 01246-903 (Brazil)

Tel. +55 113061 72811,E-Mail chelou@ usp.br 
Previous studies conducted by our laboratory demonstrated that hypercholesterolemia is associated with poor prognosis in acute renal failure [4], aggravates radiocontrast nephrotoxicity [5] and may impair renal autoregulation [6]. In these studies, the vascular factor was probably the major mechanism involved in the pathophysiology of these findings. In another study [7], maternal hypercholesterolemia was evaluated and pregnancy abnormalities were observed in the absence of hypertension. Moreover, disturbances in the development of the offspring including reduction in creatinine clearance associated with high urinary excretion of sodium, potassium and water in adulthood were also observed. Again, these observed effects were in the absence of hypertension. Thus, a nonvascular mechanism may also play a role in the development of the abnormalities induced by maternal hypercholesterolemia.

Magnesium deficiency may alter metabolism of elastin, proliferation of collagen, calcification, lipid metabolism and platelet aggregation [8]. Magnesium is the second most important intracellular cation and it functions as a cofactor for many cellular processes which include the regulation of several ion channels and the activity of $\mathrm{Na}^{+}, \mathrm{K}^{+}$-ATPase $[8,9]$. Hence, magnesium depletion may induce failure in the renal and cardiovascular systems and may induce hypercholesterolemia in humans [9-13]. It has been reported that magnesium intake is inversely associated with the incidence of type 2 diabetes [14] and the prevalence of the metabolic syndrome in older adults [15]. However, studies demonstrating that hypercholesterolemia may induce hypomagnesemia have not been carried out to date.

The aim of this study was to evaluate if hypercholesterolemia can induce abnormalities in electrolyte homeostasis due to changes in renal tubular function. Thus, a short period of high cholesterol feeding was chosen to induce hypercholesterolemia in rats. This protocol elicits cholesterol plasma without changes in blood pressure (BP), glomerular filtration rate (GFR) and renal blood flow (RBF) [6]. Although the short period of high cholesterol feeding may seem to be an acute effect of hypercholesterolemia in renal rat function, the results will have clinical relevance if the hypothesis is confirmed, especially if hypomagnesemia occurs in consequence of a renal tubular dysfunction. Thus, studies conducted in humans with long-term hypercholesterolemia will be required to evaluate magnesium homeostasis. It is possible that chronic hypercholesterolemia is in fact the cause of hypomagnesemia that is often observed in critically ill patients and which has been associated with increased morbidity and mortality in hospitalized patients $[12,13]$.

\section{Methods}

\section{Experimental Groups}

Male Wistar rats, weighing $\sim 200 \mathrm{~g}$, were randomly housed in individual cages. They were fed a standard diet or a standard diet supplemented with $4 \%(\mathrm{w} / \mathrm{w})$ cholesterol and $1 \%(\mathrm{w} / \mathrm{w})$ cholic acid for 8 days [4-7]. The animals were anesthetized with sodium thionembutal (50 $\mathrm{mg} / \mathrm{kg}$ b.w., i.p.) to perform all surgical preparations or to harvest the kidneys in the case of in vitro experiments.

This study was conducted in accordance with the guidelines of the Ethics Committee of the Hospital das Clínicas da Faculdade de Medicina da Universidade de São Paulo.

\section{Renal Blood Flow}

$\mathrm{RBF}$ was measured under anesthesia, as previously described [6]. Briefly, catheters were placed in the trachea, external jugular vein for fluid infusion and in femoral artery to measure BP. A midline incision in abdomen was made and the left renal pedicle was carefully microdissected to place an ultrasonic flow probe (T106 Transonic Systems, Bethesda, Md., USA). RBF was recorded every $10 \mathrm{~s}$ during $10 \mathrm{~min}$ for each experiment and the renal vascular resistance (RVR) was calculated as the ratio of $B P$ and RBF.

Metabolic Cage Studies

Rats fed either a standard diet or a cholesterol-enriched diet were placed in individual metabolic cages to collect urine under mineral oil for $24 \mathrm{~h}$. To avoid contamination in urine samples the diet was restricted, but they were allowed to drink water ad libitum. At the end of this period, the animals were anesthetized to collect blood samples via a PE-200 inserted into the abdominal aorta.

Urine and plasma osmolality was determined by the freezingpoint method (The Advanced Osmometer; 3D3, Mass., USA). Sodium and potassium were measured in urine and plasma by flame photometry (CELM-FC280, Brazil). The enzymatic colorimetric method (Labtest; Minas Gerais, Brazil) was used to quantify levels of magnesium, calcium, phosphorus, chloride and creatinine in urine and plasma. In the serum, total cholesterol and aldosterone were also measured using enzymatic colorimetric method and serum by radioimmunoassay, respectively (Coat-A-Count; DPC, Los Angeles, Calif., USA).

\section{Free Water Clearance}

Free water clearance $\left(\mathrm{C}_{\mathrm{H}_{2} \mathrm{O}}\right)$ was measured in another set of animals [16]. Briefly, a tracheotomy was performed and two polyethylene (PE-60) catheters were inserted in two external jugular veins for infusion of inulin and fluids. A hypotonic saline solution (150 mosm) was infused at a rate of $0.03 \mathrm{ml} / \mathrm{min}$ for $15 \mathrm{~min} \mathrm{im-}$ mediately after a jugular vein had been cannulated. Thereafter, a more hypotonic saline solution (135 mosm) was infused at different rates $(0.03,0.06$ and $0.08 \mathrm{ml} / \mathrm{min}$ ) according to the diuresis observed [16]. Subsequently, one PE-60 was inserted in a carotid artery to collect blood samples and to measure BP and one PE-240 was placed in the bladder to collect urine samples. When the surgical procedure was completed, a priming dose of inulin $(100 \mathrm{mg}$ / $\mathrm{kg}$ b.w.) was administered by a jugular vein, followed by a constant inulin infusion $(10 \mathrm{mg} / \mathrm{kg}$ b.w.) at a rate of $0.04 \mathrm{ml} / \mathrm{min}$. Blood samples were collected at the beginning and at the end of the experiment and inulin was assayed by the anthrone method in all 
blood and urine samples [17]. $\mathrm{C}_{\mathrm{H}_{2} \mathrm{O}}$ and the distal delivery of sodium chloride $\left(\mathrm{DD}_{\mathrm{NaCl}}\right)$ were calculated using the following formulas:

$$
\begin{aligned}
& \mathrm{C}_{\mathrm{H}_{2} \mathrm{O}}=\frac{\text { Urine volume }(\mathrm{ml} / \mathrm{min})-\text { Osmolar clearance }(\mathrm{ml} / \mathrm{min})}{\text { Inulin clearance }(\mathrm{ml} / \mathrm{min})} \times 100 \\
& \mathrm{DD}_{\mathrm{NaCl}}=\frac{\text { Sodium clearance }(\mathrm{ml} / \mathrm{min})+\mathrm{C}_{\mathrm{H}_{2} \mathrm{O}}(\mathrm{ml} / \mathrm{min})}{\text { Inulin clearance }(\mathrm{ml} / \mathrm{min})} \times 100
\end{aligned}
$$

\section{$\mathrm{Na}^{+}, \mathrm{K}^{+}$-ATPase Assay}

In another series of anesthetized animals, the kidneys were harvested to dissect the cortex and the outer medullas at $4^{\circ} \mathrm{C}$. The tissue fragments were homogenized with a Teflon pestle in a 20/1 $(\mathrm{v} / \mathrm{w})$ cold solution $\left(4^{\circ} \mathrm{C}\right)$ containing $0.25 \mathrm{M}$ sucrose, $6 \mathrm{~mm}$ EDTA, $20 \mathrm{~mm}$ imidazole, $2.4 \mathrm{mM}$ sodium deoxycholate ( $\mathrm{pH}$ 6.8), and filtered through a double layer of surgical gauze. The $\mathrm{Na}^{+}, \mathrm{K}^{+}$-ATPase activity was measured by the inorganic phosphate $\left(\mathrm{P}_{\mathrm{i}}\right)$ released from ATP labeled with $\gamma\left[{ }^{32} \mathrm{P}\right]$. The $\mathrm{Na}^{+}, \mathrm{K}^{+}$-ATPase activity was defined as the difference of ${ }^{32} \mathrm{P}$ liberated in total and basal ATPase assays, corrected for the spontaneous nonenzymatic breakdown of ATP and reported as $\mu \mathrm{M} \mathrm{P}_{\mathrm{i}} / \mathrm{mg}$ protein $\cdot \mathrm{h}^{-1}$, as described by Assis et al. [7].

\section{Isolation and Calcium Signaling in Isolated Nephron} Segments

After anesthesia, the medullary segments of the thick ascending limb of Henle's loop (mTAL) and collecting duct (OMCD) were isolated from collagenase-treated kidney [18, 19]. The tubules were microdissected in standard solution (composition in mM: $127 \mathrm{NaCl}, 5 \mathrm{KCl}, 0.8 \mathrm{MgSO}_{4}, 0.33 \mathrm{Na}_{2} \mathrm{HPO}_{4}$, $0.44 \mathrm{KH}_{2} \mathrm{PO}_{4}, 2 \mathrm{CaCl}_{2}$, 1-hydroxyethylpiperazine-N'-2-ethanesulfonic acid (Hepes), $\mathrm{pH} 7.4$, and $1 \mathrm{mg} / \mathrm{ml}$ bovine serum albu$\mathrm{min}$ ) at $4^{\circ} \mathrm{C}$ under a stereomicroscope (Hund GmbH, Germany). The tubules were identified by morphological and topographical criteria. Each isolated tubule was transferred to a thin glass microscope coverslip in $1 \mu \mathrm{l}$ standard solution containing $1 \%$ agarose (type IX; Sigma-Aldrich) that was fixed by cooling the slide for $5 \mathrm{~min}$ on ice. The tubules embedded in jellied agarose were then loaded with $10 \mu \mathrm{M}$ acetoxymethyl ester of fura 2 (fura 2-AM; Molecular Probes, USA) for $45 \mathrm{~min}$ at room temperature in darkness.

The glass slip with the sample was glued to the bottom of a superfusion chamber and fixed on the stage of an inverted fluorescent microscope (Nikon, Japan) equipped with Fluor $\times 40 \mathrm{ob}-$ jective to measure intracellular calcium concentration $\left(\left[\mathrm{Ca}^{2+}\right]_{\mathrm{i}}\right)$ by using a Photoscan microfluorimeter (Photon Technology International, USA). The sample was continuously superfused with the standard solution $\left(0.6 \mathrm{ml} / \mathrm{min}, 37^{\circ} \mathrm{C}\right)$ carrying or not carrying angiotensin II (Ang II) for $5 \mathrm{~min}$. The sample was alternately excited at 340 and $380 \mathrm{~nm}$ (4 s/cycle), and the fluorescence emitted at $510 \mathrm{~nm}$ from an area defined by an adjustable window (about $25 \times 30 \mathrm{~mm}$ ) was measured. Background was routinely recorded for both wavelengths at the end of each experiment and subtracted from all measurements. [20]:

$\left[\mathrm{Ca}^{2+}\right]_{\mathrm{i}}$ was calculated using the equation of Grynkiewicz et al.

$$
\left[\mathrm{Ca}^{2+}\right]_{\mathrm{i}}=\mathrm{K}_{\mathrm{d}} \times \lambda\left(\mathrm{R}-\mathrm{R}_{\min }\right) /\left(\mathrm{R}_{\max }-\mathrm{R}\right)
$$

where $\mathrm{K}_{\mathrm{d}}$ is the dissociation constant for the fura 2-Ca ${ }^{2+}$ complex, $\mathrm{R}$ is the ratio of fluorescence emitted for each wavelength (340/380), $R_{\max }$ is the maximal ratio emitted in the presence of saturating free calcium, $R_{\min }$ is the minimal ratio measured in the absence of free calcium, and $\lambda$ is the ratio of fluorescence obtained at $380 \mathrm{~nm}$ in the absence and presence of saturating free calcium. The values of $R_{\min }, R_{\max }$ and $\lambda$ were periodically determined by external calibration using a buffer kit (Molecular Probes, USA) that mimicked the intracellular medium [19].

Specific Antibodies to Aquaporin 2 (AQP2), Na, K-2Cl Cotransporter (NKCC2), Renal Outer Medullary Potassium Channel (ROMK) and Transient Receptor Potential Channel Melastatin Subtype 6 (TRPM6)

The peptide-derived polyclonal antibody specific to TRPM6 was kindly supplied by Dr. Vladimir Chubanov (Institute for Pharmacology and Toxicology, Philipps University Marburg, Marburg, Germany). The peptide-derived polyclonal antibodies specific to AQP2, ROMK and actin were obtained from Santa Cruz Biotechnology (Santa Cruz, Calif., USA) and the peptidederived polyclonal antibody specific to NKCC2 was from Millipore (USA).

\section{Preparation of Membrane Fractions}

Using a Teflon pestle glass homogenizer (Schmidt \& Co., Frankfurt am Main, Germany), cortex and medulla samples were homogenized in an ice-cold isolation solution $(200 \mathrm{mM}$ mannitol, $80 \mathrm{~mm}$ Hepes and $41 \mathrm{mM} \mathrm{KOH}, \mathrm{pH}$ 7.5) containing protease inhibitor cocktail (Sigma, St. Louis, Mo., USA). The homogenates were centrifuged at low speed $(2,000 \mathrm{~g})$ for $15 \mathrm{~min}$ at $4^{\circ} \mathrm{C}$ to remove nuclei and cell debris. The supernatants were then spun at $100,000 \mathrm{~g}$ for $1 \mathrm{~h}$ at $4^{\circ} \mathrm{C}(70 \mathrm{Ti}$ rotor; Beckman Coulter, Inc., Fullerton, Calif., USA), producing pellets containing membrane fractions enriched with plasma membranes and intracellular vesicles. The pellets were suspended in the same isolation solution.

\section{Electrophoresis and Immunoblotting}

Samples of membrane fractions were run on polyacrylamide minigels, 12\% (for AQP2 and ROMK) or 8\% (for NKCC2 and TRPM6). After transfer by electroelution to nitrocellulose membranes (PolyScreen, PVDF Transfer; NEN Life Science, Boston, Mass., USA), blots were blocked with $5 \%$ milk and $0.1 \%$ Tween 20 in phosphate-buffered saline $(\mathrm{NaCl} 8.7 \mathrm{~g} / \mathrm{l}$, dibasic phosphate 7.2 $\mathrm{mM}$ and monobasic phosphate $2.8 \mathrm{mM}$ ) for $1 \mathrm{~h}$. Blots were then incubated with anti-AQP2 antibody (1:2,000), NKCC2 antibody (1:1,000), ROMK (1:500) or TRPM6 antibody (1:500). The labeling was visualized with horseradish peroxidase-conjugated secondary antibody (anti-rabbit IgG, diluted 1:2,000, or anti-goat IgG, diluted 1:5,000; Sigma) using an enhanced chemiluminescence system (Amersham Pharmacia Biotech, Piscataway, N.J., USA).

\section{Quantitation of Renal Protein Levels}

The enhanced chemiluminescence films presenting bands within the linear range were scanned using the ImageJ (National Institute of Mental Health, Bethesda, Md., USA). These bands were normalized through evaluation of densitometric actin protein abundance. Bands corresponding to protein expression of AQP2, NKCC2, ROMK, and TRPM6 were expressed as percentages of control. 
Table 1. Body weight and hemodynamic measurements in HC and NC rats

\begin{tabular}{lllll}
\hline & $\begin{array}{l}\text { Body } \\
\text { weight } \\
\mathrm{g}\end{array}$ & $\begin{array}{l}\text { Blood } \\
\text { pressure } \\
\mathrm{mm} \mathrm{Hg}\end{array}$ & $\begin{array}{l}\text { Renal } \\
\text { blood flow } \\
\mathrm{ml} / \mathrm{min} / \\
100 \mathrm{~g} \mathrm{b.w.}\end{array}$ & $\begin{array}{l}\text { Renal } \\
\text { vascular } \\
\text { resistance } \\
\mathrm{mm} \mathrm{Hg} / \\
\mathrm{ml} / \mathrm{min}\end{array}$ \\
\hline $\mathrm{NC}(\mathrm{n}=8)$ & $229.2 \pm 3.8$ & $106.2 \pm 5.3$ & $3.80 \pm 0.18$ & $12.3 \pm 0.7$ \\
$\mathrm{HC}(\mathrm{n}=9)$ & $233.8 \pm 6.5$ & $108.0 \pm 3.2$ & $3.92 \pm 0.22$ & $12.3 \pm 1.0$ \\
\hline
\end{tabular}

Data are expressed as mean \pm SEM. There were no differences between groups.

Table 2. Characteristics of $\mathrm{HC}$ and $\mathrm{NC}$ rats during metabolic cage studies

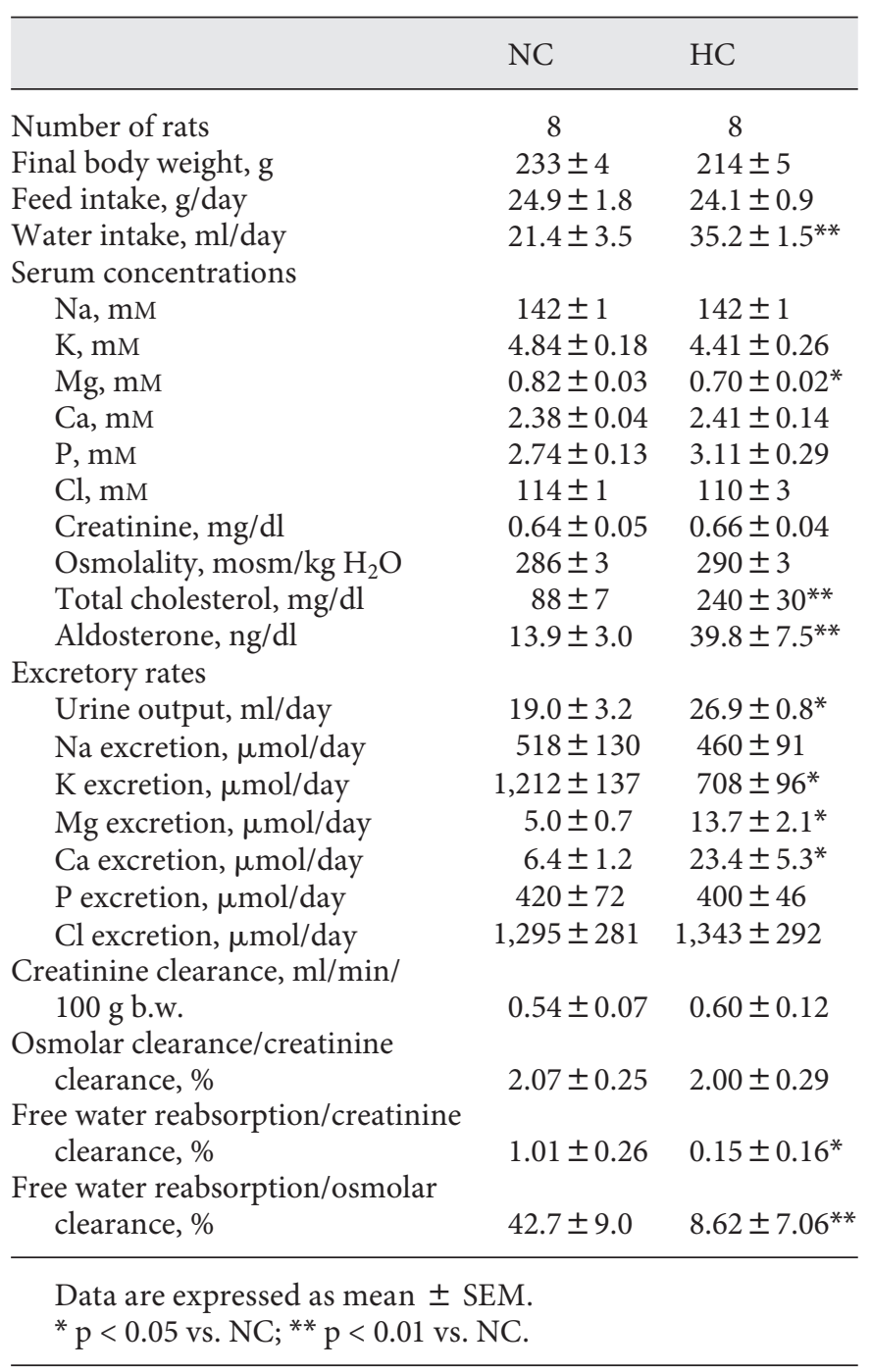

\section{Statistical Analysis}

Data are expressed as means \pm SE. Unpaired Student's t test was used for comparisons between groups and paired Student's $t$ test was used for dual comparisons on the same nephron segment between baseline and Ang II treatment. The Mann-Whitney test was used for densitometric analysis. Values of $\mathrm{p}<0.05$ were considered significant.

\section{Results}

As expected, high cholesterol feeding for 8 days did not change BP, RBF or RVR (table 1). In addition, the metabolic cage studies confirmed that high cholesterol feeding for 8 days was enough to induce hypercholesterolemia without changes in GFR that was determined by creatinine clearance (table 2).

With regard to electrolyte homeostasis, all of them were in a normal range in the serum of hypercholesterolemic rats (HC) with the exception of magnesium (table 2). It was observed that $\mathrm{HC}$ developed hypomagnesemia with a marked increase in urinary excretion of this cation (table 2). Moreover, a marked increase in urinary excretion of calcium was also observed in HC (fig. 1), and HC had a lower capacity to excrete potassium than normocholesterolemic rats (NC) despite a significant increase in serum aldosterone (fig. 2).

Concerning renal handling of water, the urine output and the water intake were significantly higher in HC than NC. Urine osmolarity and the calculus of free water reabsorption corrected for either creatinine clearance or osmolar clearance were significantly lower in $\mathrm{HC}$ than in NC (fig. 3).

\section{Free Water Clearance}

In another series of animals, the renal capacity to excrete water was evaluated. The free water clearance reached the maximum in both $\mathrm{HC}$ and $\mathrm{NC}$ with similar distal delivery of sodium chloride (fig. 4). Both HC and $\mathrm{NC}$ reduced the urinary osmolality to the same low range and it took them the same time to reach this maximal effect. However, differences in diluting capacity were observed between $\mathrm{HC}$ and $\mathrm{NC}$ when the free water clearance was correlated with the distal delivery of sodium chloride. As can be seen in figure 5, the free water clearance was low when the distal delivery of sodium chloride was also low. On the other hand, when the distal delivery of sodium chloride was elicited, the magnitude of the free water clearance in $\mathrm{HC}$ was proportionally lower than in $\mathrm{NC}\left(\mathrm{F}_{\mathrm{o}}=34.96>\mathrm{F} \alpha=4.085, \mathrm{p}<0.0001\right)$. 
Fig. 1. Urinary excretion of magnesium (a) and calcium (b) in $\mathrm{HC}, \mathrm{n}=8$, and $\mathrm{NC}$ rats, $\mathrm{n}=8$. Data are means \pm SEM. $\mathrm{p}<0.01$ as compared with NC.
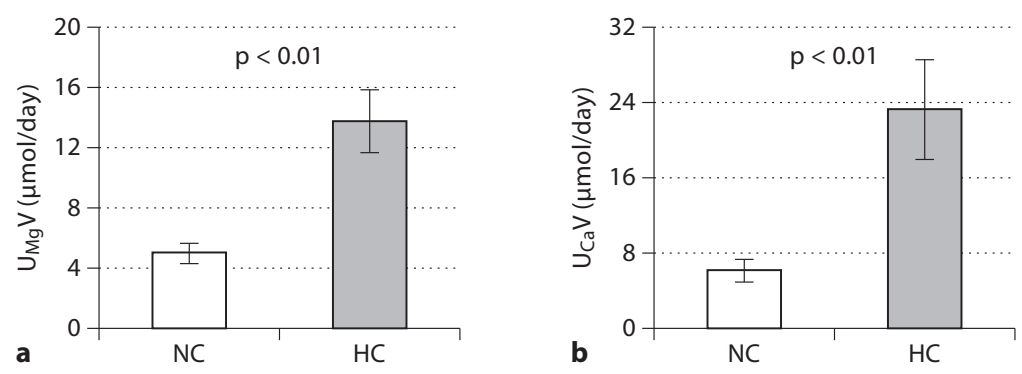

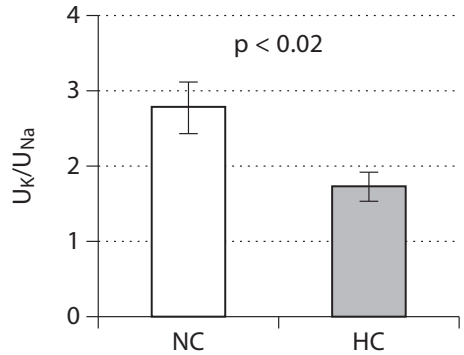

a
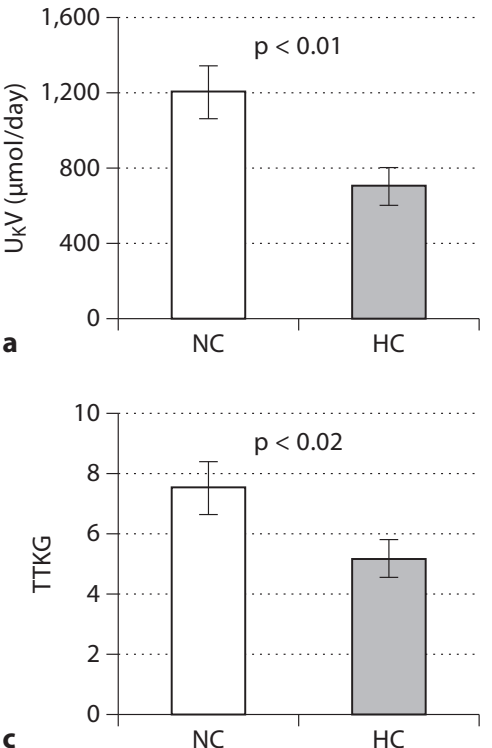

b

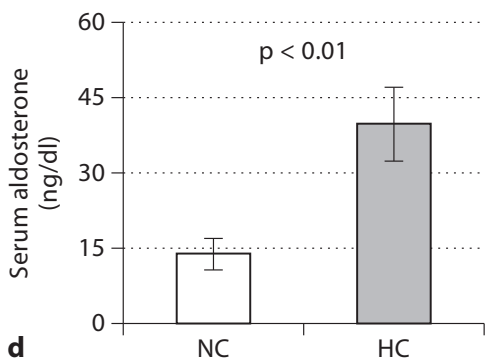

Fig. 2. Capacity to excrete potassium in $\mathrm{HC}$, $\mathrm{n}=8$, and $\mathrm{NC}$ rats, $\mathrm{n}=8$. a Urinary excretion of potassium $\left(\mathrm{U}_{\mathrm{K}} \mathrm{V}\right)$. $\mathbf{b}$ Urinary potassium/sodium ratio $\left(\mathrm{U}_{\mathrm{K}} / \mathrm{U}_{\mathrm{Na}}\right)$. c Trans-tubular potassium gradient (TTKG). d Serum aldosterone. Data are means \pm SEM. $\mathrm{p}<$ 0.01 and $\mathrm{p}<0.02$ as compared with NC.

\section{$\mathrm{Na}^{+}, \mathrm{K}^{+}$-ATPase Activity}

As illustrated in figure 6 , the $\mathrm{Na}^{+}, \mathrm{K}^{+}$-ATPase activity in cortex and outer medulla of $\mathrm{HC}$ did not differ from that measured in NC.

\section{Calcium Signaling in $\mathrm{TTAL}$ and $\mathrm{OMCD}$}

$\left[\mathrm{Ca}^{2+}\right]_{\mathrm{i}}$ responses to $10^{-7} \mathrm{M}$ Ang II were tested in isolated medullary nephron segments. Either mTAL or OMCD microdissected from NC and HC kidneys responded to Ang II (table 3). However, mTAL of HC kidneys showed higher sensitivity to Ang II than mTAL of NC kidneys (fig. 7). In contrast, the magnitude of response to Ang II in OMCD of HC did not differ from NC.
Immunoblot Using Membrane Fractions Prepared from Renal Cortex Samples to TRPM6 and Renal Medulla Samples to AQP2, NKCC2 and ROMK

As demonstrated in table 4 and illustrated in figure 8, TRPM6 protein expression was significantly reduced in the renal cortical membrane fractions of $\mathrm{HC}$ than in NC. In addition, NKCC2 and ROMK protein expressions were significantly higher in renal outer medulla fractions in HC than in NC. With regard to AQP2, its protein expression in renal outer medulla fraction of $\mathrm{HC}$ did not differ from that measured in NC. 


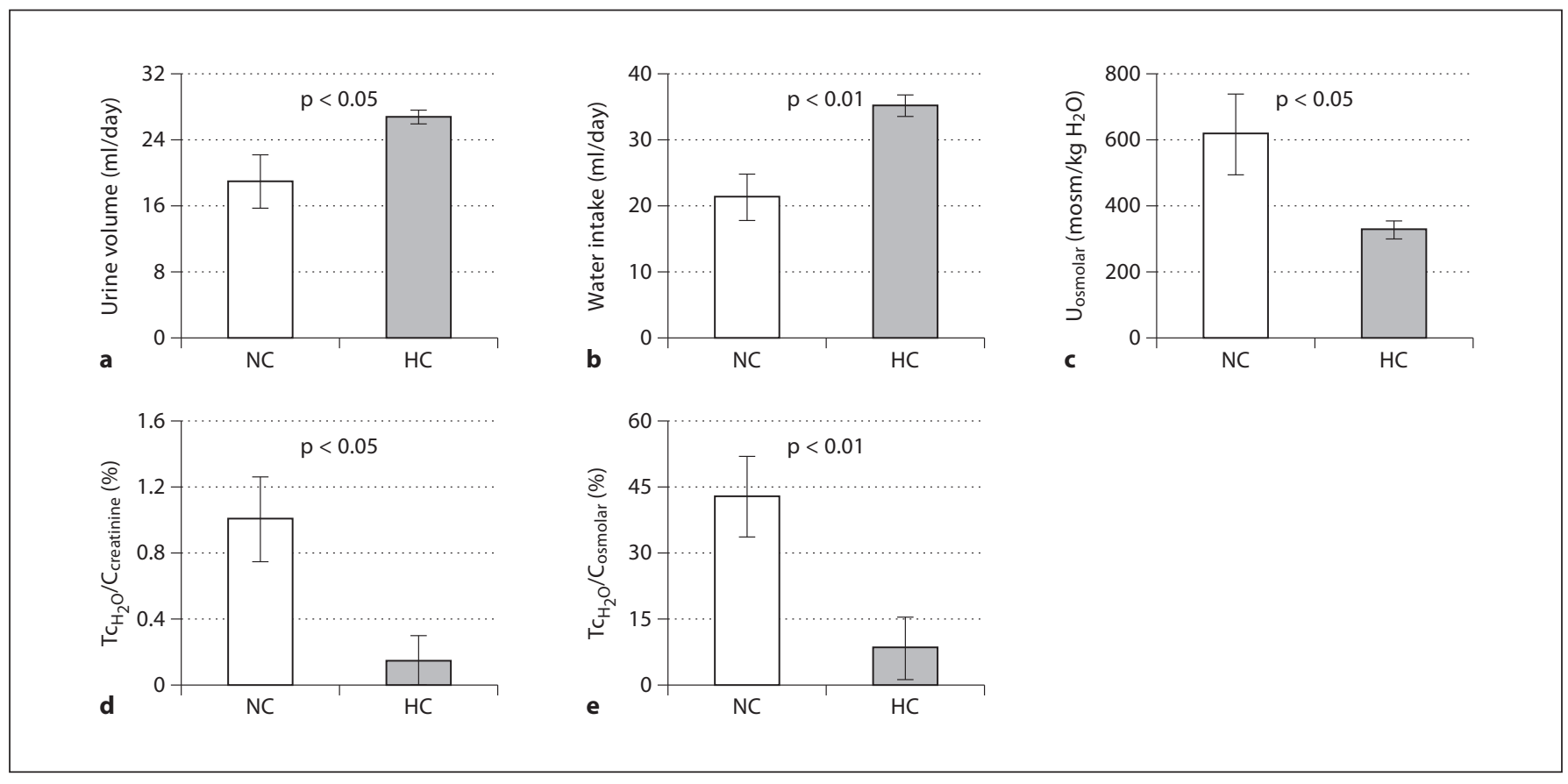

Fig. 3. Capacity to reabsorb free water in $\mathrm{HC}, \mathrm{n}=8$, and $\mathrm{NC}$ rats, $\mathrm{n}=8$. a Urine volume. b Water intake. $\mathbf{c}$ Urine osmolality $\left(\mathrm{U}_{\mathrm{osmolar}}\right)$. d Free water reabsorption corrected for creatinine clearance $\left(\mathrm{Tc}_{\mathrm{H}_{2} \mathrm{O}} / \mathrm{C}_{\text {creatinine }}\right)$. e Free water reabsorption corrected for osmolar clearance $\left(\mathrm{Tc}_{\mathrm{H}_{2} \mathrm{O}} / \mathrm{C}_{\text {osmolar }}\right)$. Data are means \pm SEM. $\mathrm{p}<0.01$ and $\mathrm{p}<0.05$ as compared with NC.

Fig. 4. Capacity to eliminate free water in $\mathrm{HC}, \mathrm{n}=6$, and NC rats, $\mathrm{n}=7$. $\mathrm{a}$ The maximal capacity to dilute urine determined by free water excretion corrected for inulin clearance $\left(\mathrm{C}_{\mathrm{H}_{2} \mathrm{O}} / \mathrm{C}_{\text {inulin }}\right)$. b The urinary osmolarity $\left(\mathrm{U}_{\text {osmolar }}\right)$ reached at the maximal capacity to dilute urine. c Time elapsed to reach the maximal capacity to dilute urine. $\mathbf{d}$ Distal delivery of sodium chloride corrected for inulin clearance $\left(\mathrm{DD}_{\mathrm{NaCl}} /\right.$ $\left.\mathrm{C}_{\text {inulin }}\right)$. Data are means \pm SEM.
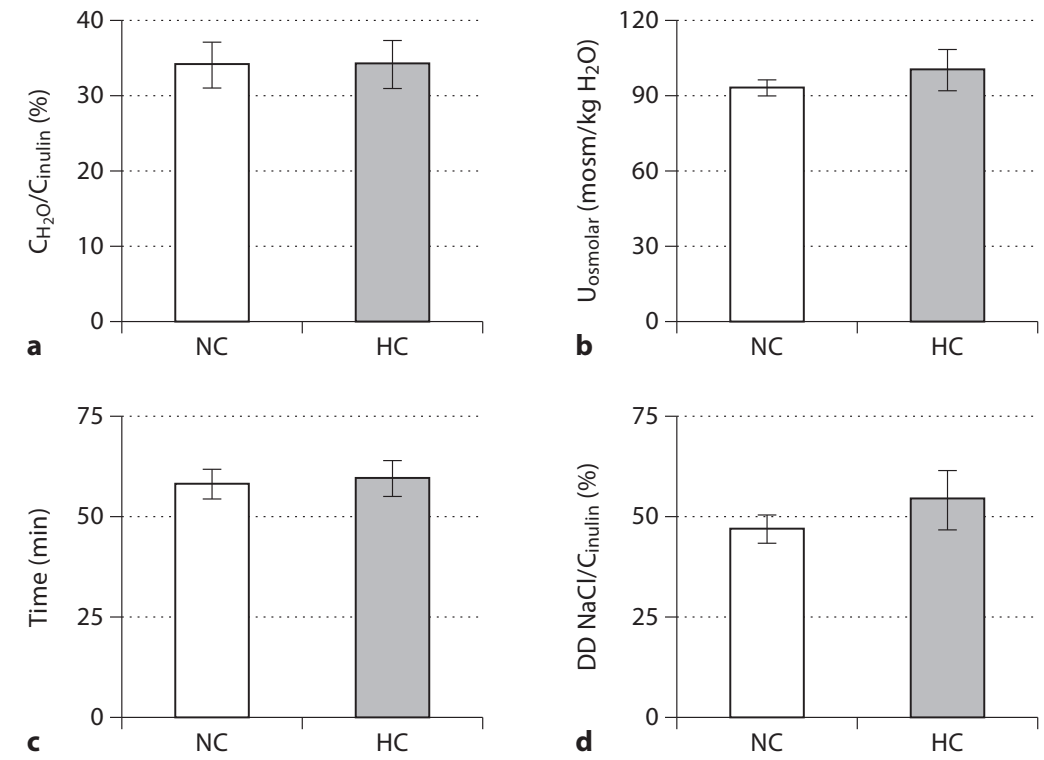


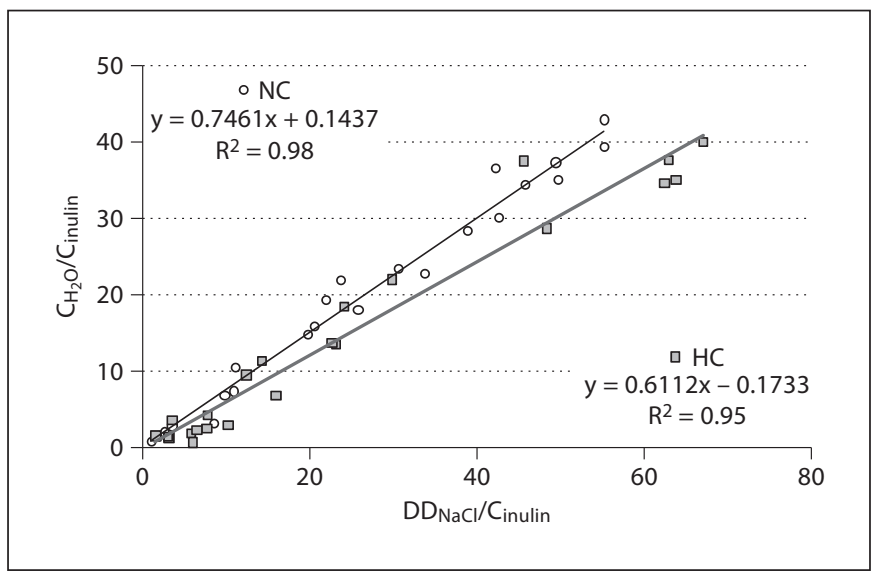

Fig. 5. Magnitude of the free water clearance corrected for inulin clearance $\left(\mathrm{C}_{\mathrm{H}_{2} \mathrm{O}} / \mathrm{C}_{\text {inulin }}\right)$ plotted against the distal delivery of sodium chloride corrected for inulin clearance $\left(\mathrm{DD}_{\mathrm{NaCl}} / \mathrm{C}_{\text {inulin }}\right)$ in $\mathrm{HC}, \mathrm{n}=6$, and $\mathrm{NC}$ rats, $\mathrm{n}=7$.

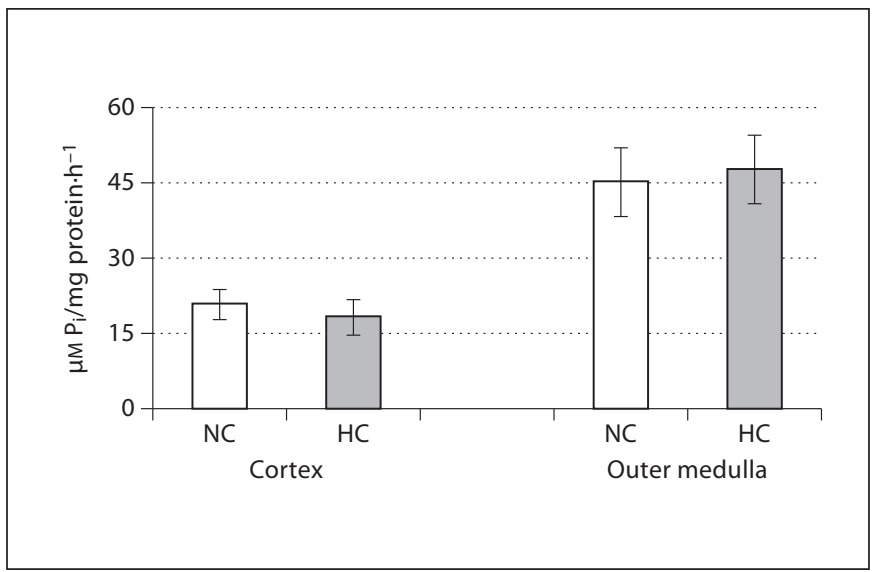

Fig. 6. $\mathrm{Na}^{+}, \mathrm{K}^{+}$-ATPase activity measured in the cortex and the outer medulla in $\mathrm{HC}, \mathrm{n}=6$, and $\mathrm{NC}$ rats, $\mathrm{n}=6$. Data are means \pm SEM.
Fig. 7. In vitro studies using cytosolic $\left.\left[\mathrm{Ca}^{2+}\right]_{\mathrm{i}}\right]$ responses to $10^{-7} \mathrm{M}$ Ang II measured in a medullary segment of the mTAL (a) and an outer medullary collecting duct (OMCD) (b) microdissected from HC and NC rats. Data are mean \pm SEM. $\mathrm{p}<0.05$ as compared with NC.
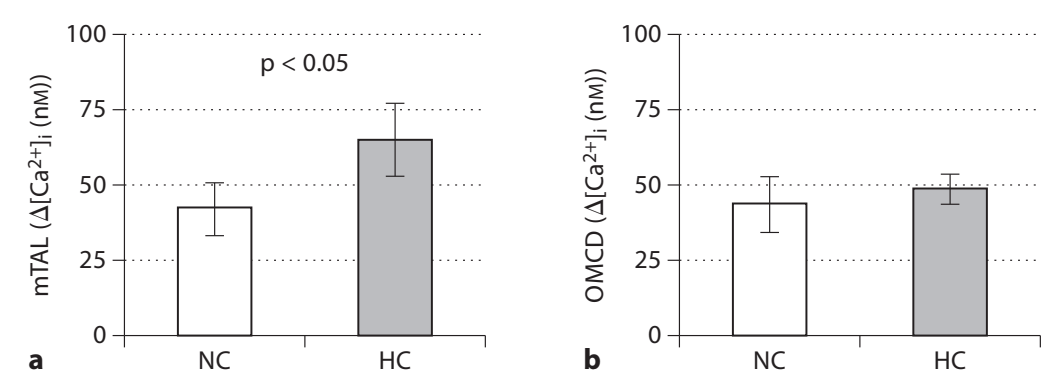

Table 3. $\left[\mathrm{Ca}^{2+}\right]_{\mathrm{i}}$ responses to $10^{-7} \mathrm{M}$ Ang II in medullary nephron segments microdissected from kidneys of $\mathrm{HC}$ and NC rats

\begin{tabular}{|c|c|c|c|c|c|c|c|c|}
\hline & \multicolumn{4}{|c|}{ mTAL } & \multicolumn{4}{|c|}{ OMCD } \\
\hline & $\mathrm{n}$ & basal & Ang II & $\Delta\left[\mathrm{Ca}^{2+}\right]_{\mathrm{i}}$ & $\mathrm{n}$ & basal & Ang II & $\Delta\left[\mathrm{Ca}^{2+}\right]_{\mathrm{i}}$ \\
\hline $\mathrm{NC}$ & 7 & $66 \pm 6$ & $109 \pm 11^{*}$ & $42 \pm 8$ & 7 & $88 \pm 8$ & $130 \pm 16^{*}$ & $42 \pm 9$ \\
\hline $\mathrm{HC}$ & 6 & $70 \pm 7$ & $135 \pm 8^{*}$ & $65 \pm 12^{* *}$ & 7 & $101 \pm 9$ & $147 \pm 11$ & $47 \pm 5$ \\
\hline
\end{tabular}

Data are expressed as mean \pm SEM.

$\Delta\left[\mathrm{Ca}^{2+}\right]_{\mathrm{i}}=$ Variation in intracellular calcium concentration.

${ }^{*} \mathrm{p}<0.01$ vs. basal; ${ }^{* *} \mathrm{p}<0.05$ vs. mTAL of NC and OMCD of NC and HC.

\section{Discussion}

This study showed that high cholesterol feeding in rats induced hypomagnesemia with high magnesium urinary losses due to a reduction in the expression of epithelial
$\mathrm{Mg}^{2+}$ channel in the renal cortex. Additionally, increases in urinary excretion of $\mathrm{Ca}^{2+}$ and a reduction in the capacity to excrete $\mathrm{K}^{+}$were also observed in $\mathrm{HC}$. All these tubular dysfunctions occurred in the absence of a vascular mechanism. 


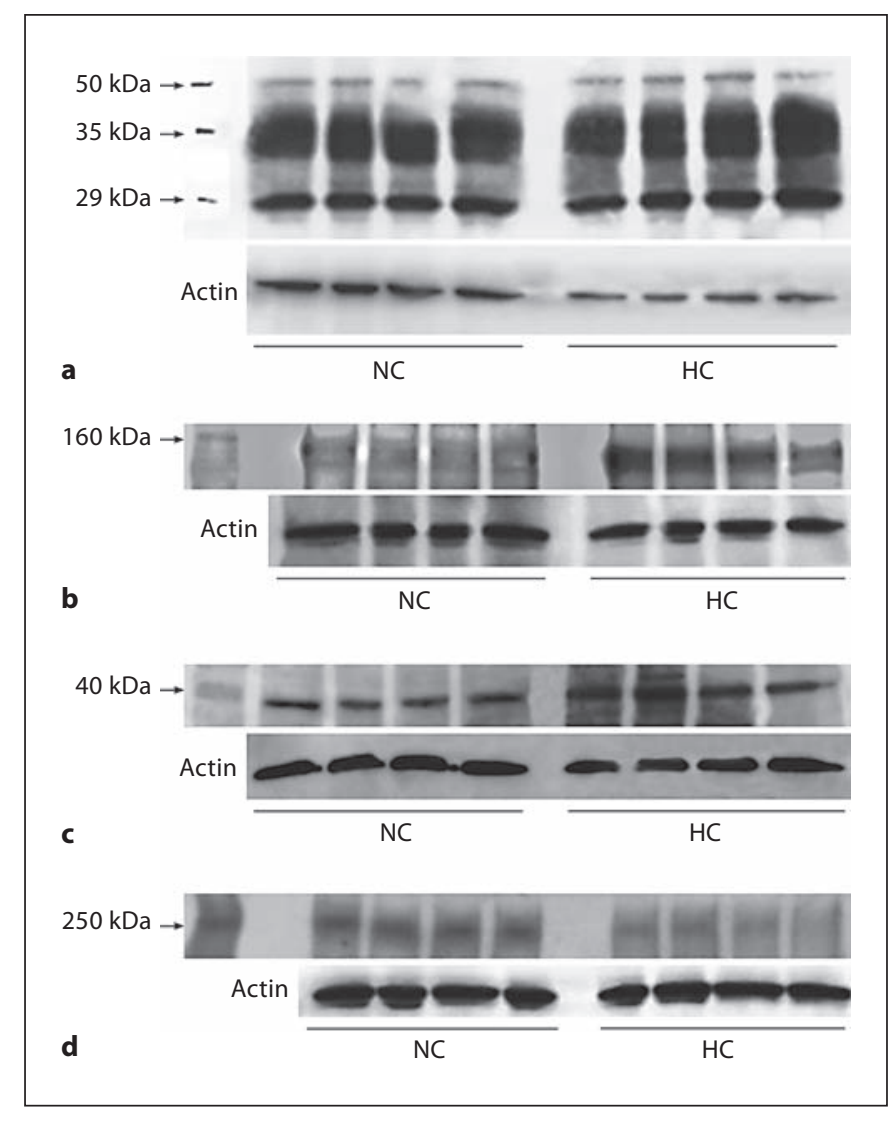

Fig. 8. Immunoblotting of membrane fractions prepared from kidney cortex and medulla samples: AQP2 (a), NKCC2 (b), ROMK (c), and TRPM6 (d).

In agreement with our previous study, BP, GFR, RBF and RVR values remained within the normal range in the rats feeding a high cholesterol diet for 8 days [6]. Thus, the results will be analyzed considering the characteristics of each nephron segment transport in order to verify which nephron segment could be targeted by hypercholesterolemia.

The possibility that changes in the proximal tubule function occurred was not considered because the phosphorus filtered is reabsorbed in the proximal tubule and the urinary excretion of phosphorus was similar in $\mathrm{HC}$ and NC. Moreover, the distal delivery of sodium chloride measured in free water clearance experiments did not differ between $\mathrm{HC}$ and NC.

The chances of impairment in TAL would be expected because $\mathrm{HC}$ showed high magnesium and calcium urinary losses and less capacity to reabsorb and eliminate free water. However, urinary sodium excretion in $\mathrm{HC}$ was similar to NC.
Table 4. Quantitation of immunoblotting of membrane fractions prepared from kidney cortex and medulla samples; densitometric analysis of all samples from kidneys of $\mathrm{HC}$ and $\mathrm{NC}$ rats

\begin{tabular}{lrlll}
\hline & \multicolumn{1}{l}{ AQP2 } & NKCC2 & ROMK & \multicolumn{1}{c}{ TRPM6 } \\
\hline NC $(\mathrm{n}=8)$ & $100.5 \pm 3.0$ & $102.4 \pm 3.0$ & $106 \pm 4.4$ & $101.4 \pm 1.5$ \\
HC $(\mathrm{n}=8)$ & $98.0 \pm 5.5$ & $138.1 \pm 4.4^{* *}$ & $128 \pm 8.1^{*}$ & $66.6 \pm 3.1^{* *}$ \\
\hline
\end{tabular}

Data are expressed as mean \pm SEM.

${ }^{*} \mathrm{p}<0.05$ vs. NC; ${ }^{* *} \mathrm{p}<0.001$ vs. NC.

It is well known that a NKCC2 is expressed in the apical side in TAL resulting in transcellular reabsorption of sodium chloride, which is the initial step for the countercurrent mechanism. For this reason, TAL is the decisive nephron segment to form concentrated or diluted urine [21-23]. In consequence of chloride reabsorption, a lumen-positive voltage is generated, allowing passive paracellular transport of $\mathrm{Ca}^{2+}$ and $\mathrm{Mg}^{2+}[11,21]$. The protein kinase A, 20-hydroxyeicosatetraenoic acid and nitric oxide regulate the NKCC2 by inhibiting its action [24, 25].

Considering that increments in oxidized lipoproteins increase the arachidonic acid metabolites and activate phospholipase $\mathrm{A}_{2}$ [2], an inhibition in the NKCC2 could be expected.

Actually, an increment in the expression of NKCC2 was observed in renal medulla samples of $\mathrm{HC}$ that justifies the similar urinary sodium excretion in $\mathrm{HC}$ compared to NC. NKCC2 expression may be elicited due to a decrease in renal nitric oxide production caused by hypercholesterolemia. Studies by our laboratory in which rats were also fed a high-cholesterol diet showed benefits in renal function with L-arginine supplementation, suggesting decreases in nitric oxide production $[4,5]$. In a recent study, Kopkan et al. [26] demonstrated that infusions of cholesterol into the renal artery in rats induced antinatriuresis and antidiuresis. They showed that these effects were mediated by a decrease in nitric oxide production which stimulated the NKCC2.

In vitro tests measuring variations in $\left[\mathrm{Ca}^{2+}\right]_{\mathrm{i}}$ demonstrated that $\mathrm{HC}$ have also shown high sensitivity to Ang II in mTAL. This finding may be associated with the increases in the expression of NKCC2 in renal medulla samples of HC.

Taken together, the hypothesis that high urinary losses of divalent cation were due to impairment in TAL was not supported. 
The distal nephron segment was also evaluated and the expression of TRPM6 was measured. This divalent cationpermeable channel is located at the luminal side of the distal convoluted tubule and is responsible for the influx of $\mathrm{Mg}^{2+}$ across the luminal membrane [11]. A reduced expression of TRPM6 in renal cortical of $\mathrm{HC}$ was observed, which explains high losses of $\mathrm{Mg}^{2+}$ in urine and the development of hypomagnesemia. Expression of other transporter proteins, such as TRV5 that is responsible for calcium reabsorption in distal convoluted tubule, may be also reduced. In addition, the free water clearance results also suggest impairment in distal convoluted tubule. Both $\mathrm{HC}$ and $\mathrm{NC}$ reached the maximum capacity to dilute urine. However, when the delivery of $\mathrm{NaCl}$ elicited, the free water clearance in $\mathrm{HC}$ was proportionally lower than in NC. The urinary diluting mechanism requires a generation of hypotonic fluid to reach the collecting duct. Thus, reduction in the ionic transport capacity in distal convoluted tubule may prevent a less hypotonic fluid from reaching the collecting duct in conditions of maximum free water diuresis.

With regard to the collecting duct, the $\left[\mathrm{Ca}^{2+}\right]_{\mathrm{i}}$ responses to Ang II and the expression of AQP2 did not differ between $\mathrm{HC}$ and $\mathrm{NC}$, suggesting that high-cholesterol feeding did not induce abnormalities in this nephron segment. However, a reduction in the capacity to excrete $\mathrm{K}^{+}$ was observed in HC.

It is well established that collecting duct cells are responsible for $\mathrm{K}^{+}$secretion which is coupled with $\mathrm{Na}^{+}$reabsorption [27]. The $\mathrm{Na}^{+}, \mathrm{K}^{+}$-ATPase present in basal membrane releases the energy, allowing sodium reabsorption through the amiloride-sensitive epithelial $\mathrm{Na}^{+}$ channel $(\mathrm{ENaC})$. A lumen-negative voltage is generated, favoring the secretion of $\mathrm{K}^{+}$through ROMK channels. Aldosterone plays an important role by increasing the activity of $\mathrm{Na}^{+}, \mathrm{K}^{+}$-ATPase and $\mathrm{ENaC}$ function which favors $\mathrm{K}^{+}$secretion [27].

In this study, a significant increment in serum aldosterone was observed in HC. The possibility of the activation of the renin-angiotensin system was thought, but it was not justified. The plasma chloride levels and the urinary excretion of chloride in $\mathrm{HC}$ were within the normal range, suggesting euvolemia in these animals. Moreover, Andrade et al. [5], using the same protocol to induce hypercholesterolemia, demonstrated that changes in volume status do not occur in HC. Thus, a possible explanation for high aldosterone serum levels may be attributed to the need to maintain potassium homeostasis. In chronic renal failure, high levels of aldosterone are present even in the presence of expanded extracellular volume $[28,29]$. In recent reviews, Arroyo et al. [30] and Hoorn et al. [31] described the aldo- sterone paradox in which aldosterone plays a role in regulating $\mathrm{K}^{+}$in collecting duct cells in the absence of Ang II action. In this situation, aldosterone is required to maintain $\mathrm{K}^{+}$homeostasis and hypovolemia is not present. The mechanism is not totally known, but interactions of aldosterone and several serine/threonine kinases, especially WNK4, with ion transport proteins have been suggested, like activation of ROMK and $\mathrm{ENaC}$ channels.

In this study, the expression of ROMK was increased in $\mathrm{HC}$, but the capacity to excrete $\mathrm{K}^{+}$was reduced and the $\mathrm{Na}^{+}, \mathrm{K}^{+}$-ATPase activity did not increase in $\mathrm{HC}$ in the presence of high aldosterone serum levels.

The $\mathrm{Na}^{+}, \mathrm{K}^{+}$-ATPase activity in $\mathrm{HC}$ was twofold higher in homogenates from the outer medulla than from the cortex, which is considered within the normal range $[7,32$, 33]. It is possible that $\mathrm{Mg}^{2+}$ deficiency could be responsible for the absence of increments in the $\mathrm{Na}^{+}, \mathrm{K}^{+}$-ATPase activity in HC. We may hypothesize that a difficulty to maintain $\mathrm{K}^{+}$homeostasis may take a place, which resulted in an increment in aldosterone secretion that elicited the expression of ROMK by a stimulation of WNK4.

In conclusion, hypercholesterolemia induced tubular dysfunctions in the absence of hemodynamic abnormalities like high magnesuria due to a reduction in the expression of TRPM6 in the renal cortex, allowing the development of hypomagnesemia. Considering that hypomagnesemia is a risk factor to increase mortality rate, the control of the plasma $\mathrm{Mg}^{2+}$ concentration in $\mathrm{HC}$ patients is justified and required.

\section{Acknowledgements}

Supported by Fundação de Amparo à Pesquisa do Estado de São Paulo (FAPESP), Laboratório de Investigação Médica (LIMHC-FMUSP) and Fundação Faculdade de Medicina (FFM).

\section{Disclosure Statement}

The authors have no conflicts to interest to disclose.

References $D_{1}$ Hansson GK, Robertson AK, SöderbergNauclér C: Inflammation and atherosclerosis. Annu Rev Pathol Mech Dis 2006;1:297329.

2 Wilensky RL, Macphee CH: Lipoprotein-associated phospholipase $\mathrm{A}_{2}$ and atherosclerosis. Curr Opin Lipidol 2009;20:415-420.

-3 Chade AR, Lerman A, Lerman LO: Kidney in early atherosclerosis. Hypertension 2005; 45:1042-1049. 
-4 Campos SB, Ori M, Dorea EL, Seguro AC: Protective effect of L-arginine on hypercholesterolemia-enhanced renal ischemic injury. Atherosclerosis 1999;143:327-334.

$\checkmark 5$ Andrade L, Campos SB, Seguro AC: Hypercholesterolemia aggravates radiocontrast nephrotoxicity: protective role of L-arginine. Kidney Int 1998;53:1736-1742.

6 Tamaoki L, Oshiro-Monreal F, Helou CMB: Effects of nicotine exposure on renal function of normal and hypercholesterolemic rats. Am J Nephrol 2009;30:377-382.

7 Assis SM, Seguro AC, Helou CMB: Effects of maternal hypercholesterolemia on pregnancy and development of offspring. Pediatric Nephrol 2003;18:328-334.

8 Altura BM, Altura BT: Magnesium and cardiovascular biology: an important link between cardiovascular risk factor and atherogenesis. Cell Mol Biol Res 1995;41:347-359.

$\checkmark 9$ Gupta BK, Glicklich D, Tellis VA: Magnesium repletion therapy improves lipid metabolism in hypomagnesemic renal transplant recipients: a pilot study. Transplantation 1999;67:1485-1487.

10 Rayssiguier Y: Role of magnesium and potassium in the pathogenesis of arteriosclerosis. Magnesium 1984;3:226-238.

11 Glaudemans B, Knoers NV, Hoenderop JG Bindels RJ: New molecular players facilitating $\mathrm{Mg}^{2+}$ reabsorption in the distal convoluted tubule. Kidney Int 2010;77:17-22.

12 Agus ZS: Hypomagnesemia. J Am Soc Nephrol 1999;10:1616-1622.

-13 Kraft MD, Btaiche IF, Sacks GS, Kudsk KA: Treatment of electrolyte disorders in adult patients in the intensive care unit. Am J Health Syst Pharm 2005;62:1663-1681.

-14 Larsson SC, Wolk A: Magnesium intake and risk of type 2 diabetes: a meta-analysis. J Intern Med 2007;262:208-214.
15 McKeown NM, Jacques PF, Zhang XL, Juan W, Sahyoun NR: Dietary magnesium intake is related to metabolic syndrome in older Americans. Eur J Nutr 2008;47:210-216.

16 Helou CMB, Leão MI, Shimizu MH, Seguro AC, Rocha AS: Comparisons of models of cortical necrosis with segmental infarction. Renal Physiol Biochem 1992;15:150-158.

17 Führ J, Kaczmarczyk J, Krüttgen CD: Eine einfache colorimetrische Methode zur Inulinbestimmung für Nieren-Clearance - Untersuchungen bei Stoffwechselgesunden und Diabetikern. Klin Wochenschr 1955;33:729730 .

18 Doucet A, Katz AI, Morel F: Determination of Na,K-ATPase activity in single segments of the mammalian nephron. Am J Physiol 1979;237:F105-F113.

19 Taniguchi S, Marchetti J, Morel F: Cytosolic free calcium in single microdissected rat collecting tubules. Pflügers Arch 1989;414:125133.

20 Grynkiewicz G, Poenie M, Tsien R: A new generation of $\mathrm{Ca}^{2+}$ indicators with greatly improved fluorescence properties. J Biol Chem 1985;260:3440-3450.

21 Bindels RJ: A molecularly guided tour along the nephron. Pflügers Arch 2009;458:1-3.

22 Greger R: Ion transport mechanisms in thick ascending limb of Henle's loop of mammalian nephron. Physiol Rev 1985;65:760-795.

23 Knepper MA, Hoffert JD, Packer RK, Fenton RA: Urine concentration and dilution; in Brenner BM (ed): Brenner \& Rector's The Kidney. Philadelphia, Saunders Elsevier, 2008, vol 1, pp 308-329.
24 Amlal H, Legoff C, Vernimmen C, Paillard $\mathrm{M}$, Bichara $\mathrm{M}: \mathrm{Na}^{+}, \mathrm{K}^{+}\left(\mathrm{NH}_{4}{ }^{+}\right)-2 \mathrm{Cl}^{-}$cotransport in medullary thick ascending limb: control by PKA, PKC, and 20-HETE. Am J Physiol 1996;271:C455-C463.

25 Ortiz PA, Hong NJ, Garvin JL: NO decreases thick ascending limb chloride absorption by reducing $\mathrm{Na}^{+}, \mathrm{K}^{+}-2 \mathrm{Cl}^{-}$cotransporter activity. Am J Physiol 2001;281:F819-F825.

-26 Kopkan L, Khan MA, Lis A, Awayda MS, Majid DS: Cholesterol induces renal vasoconstriction and anti-natriuresis by inhibiting nitric oxide production in anesthetized rats. Am J Physiol 2009;297:F1606-F1613.

27 Mount DB, Yu AS: Transport of inorganic solutes: sodium, chloride, potassium, magnesium, calcium and phosphate; in Brenner BM (ed): Brenner \& Rector's The Kidney. Philadelphia, Saunders Elsevier, 2008, vol 1, pp 185-192.

28 Shimizu MH, Coimbra TM, de Araujo M, Menezes LF, Seguro AC: N-acetylcysteine attenuates the progression of chronic renal failure. Kidney Int 2005;68:2208-2217.

29 Ibrahim HN, Hostetter TH: Aldosterone in renal disease. Curr Opin Nephrol Hypertens 2003;12:159-164.

30 Arroyo J P, Ronzaud C, Lagnaz D, Staub O, Gamba G: Aldosterone paradox: differential regulation of ion transport in distal nephron. Physiology 2011;26:115-123.

31 Hoorn EJ, Nelson JH, McCormick JA, Ellison DH: The WNK kinase network regulating sodium, potassium, and blood pressure. J Am Soc Nephrol 2011;22:605-614.

-32 Katz A: Renal Na,K-ATPase: its role in tubular sodium and potassium transport. Am J Physiol 1982;242:F207-F219.

$\checkmark 33$ Helou CMB, Seguro AC, Rocha AS: Evaluation of human kidney viability during cold storage. Ren Fail 1993;15:85-91. 